\title{
Turning the Art of Interface Design into Engineering
}

\author{
Jef Raskin \\ 8 Gypsy Hill Road \\ Pacifica, CA 94044 \\ JefRaskin@aol.com
}

The name of this conference begins with the word "engineering," a skill that I've seen little of in the world of commercial interface design. Here's what I mean by "engineering":

I don't know if my background is typical, but I've enjoyed designing aircraft for some years now. As a child, I built model airplanes, some of which flew. Of necessity, they had many adjustable parts. I could move the wing forward and aft in a slot or with rubber bands, add bits of clay to the nose to adjust the balance, and I'd glue small aluminum tabs to wings and tail surfaces and bend them to correct the flight path.

Once I had gotten past calculus and some college physics, I began to study aerodynamic and mechanical engineering more seriously. I remember with considerable pleasure the first time I was able to design a model (radio-controlled by this time) based on knowledge sound and deep enough so that I knew that --barring accidents--the aircraft would fly, and even how it would fly. I opened the throttle, the plane chugged along the runway and rose into the air, exactly as predicted. It flew and maneuvered, and I brought it back to a gentle landing.

That's engineering. The ability to design from rational foundations, numerically predict performance, and have the result work much as expected without all kinds of ad hoc adjustments.

This is not what I see in interface design. Working in the practical world of the interface designers who produce the commercial products used by millions, even hundreds of millions of people, I find that most of the practitioners have no knowledge of existing engineering methods for designing human-computer interfaces (for example, Fitts' and Hick's laws, GOMS analyses, and measures of interface efficiency). The multiple stupidities of even the latest designs, such as Microsoft's Windows 2000 or Apple's OS X, show either an unjustifiable ignorance of or a nearcriminal avoidance of what we do know.

My talk will look at some of the true engineering techniques available to us, and where HCI can go if we allow these techniques -- rather than inertia, custom, guesswork, and fear -- to guide us. 